\title{
Personality Factors Determine the Attitudes toward Eating Behavior
}

\author{
Miki Adachi ${ }^{1} \&$ Keisuke Adachi ${ }^{2}$ \\ ${ }^{1}$ Institute for Liberal Arts and Sciences, Osaka Electro-Communication University, Neyagawa, Osaka, Japan \\ ${ }^{2}$ Kobe Gakuin University, Kobe, Hyogo, Japan \\ Correspondence: Miki Adachi, Institute for Liberal Arts and Sciences, Osaka Electro-Communication University, \\ Neyagawa Campus 18-8 Hatsucho, Neyagawa-shi, Osaka, 572-8530, Japan.
}

Received: June 17, 2021

doi:10.5539/ijps.v13n3p38
Accepted: July 6, 2021

Online Published: July 9, 2021

\begin{abstract}
The purpose of this study was to clarify the personality factors that determine the difference in perception of how the order of eating and the mechanisms by which these factors operate, focusing on the attitudes toward eating behavior of eating what you like first or leaving them behind. We tested the following hypotheses about comparisons of people who eat what they like first and people who eat what they like later: (1) Perfectionism scores of those who eat later will be higher than the corresponding scores of those who eat first, (2) Optimism scores of those who eat first will be higher than the corresponding scores of those who eat later. We found that the difference in attitude toward eating behavior between first and later are related to the difference in optimism and perfectionist tendencies against the background of habituation and automation of eating behavior patterns. Although attitudes toward eating behavior are experienced by all people, they have been habituated and automated by individuals independently.
\end{abstract}

Keywords: attitude toward eating behavior, self-control, perfectionism, optimism

\section{Introduction}

Imagine having a meal with several different dishes in front of you-some of these you dislike, but others include your favorite food. Do you eat your favorite food first, or do you leave it for later? There are several possible answers to this question that reflect different attitudes toward eating behavior. Some might say, "I want to enjoy it while it's fresh, so I won't have to eat it later when I'm full." Others would say, "It's more memorable to save what I like until the end." This might be due to differences in perception of how the eating order can improve one's utility and emotions.

Dohle, Diel, and Hofmann (2018) reviewed the relationship between self-regulation of eating behavior and executive function, including working memory capacity, behavioral inhibition, and task switching. However, healthy eating behavior and self-control are not limited to refraining from unhealthy foods and encouraging healthy eating habits. It is also helpful to examine the role of emotions and benefits to individuals are experienced during "a meal in everyday life". It is also essential to focus on a meal in everyday life that efficiently promotes long-term behavioral changes to healthy eating habits. The influence of individual differences in eating order - eating what you like first or leaving it for later-is crucial for understanding highly effective eating behaviors. Therefore, it is essential to understand how an individual's personality factors interact with the eating order. This study clarifies the personality factors that determine this difference and the mechanisms by which these factors operate.

\subsection{Eating Behavior and Self-Control}

Eating behavior is an appetite-based behavior that is one of the basic physiological needs (e.g., Maslow's hierarchy of needs). As people grow and develop, they form attitudes toward eating behavior. Previous studies have examined the relationship between eating behavior and individual differences. Buffet visits are positively correlated with self-kindness and negatively correlated with awareness and mindful eating (Ali, Wong, Egan, Cook, \& Mantzios, 2017). Mindfulness promotes healthier eating behavior (Jordan, Wang, Donatoni, \& Meier, 2014) and benefits self-control to pursue long-term goals (Leyland, Rowse, \& Emerson, 2019). The weight of evidence supports the use of self-control (Baumeister, Tice, \& Vohs, 2018; Scholer, Miele, Murayama, \& Fujita, 2018). There is evidence that self-control is related to eating behavior. Trait self-control is known to be indirectly 
associated with reduced snack intake through a low desire for unhealthy eating behavior (Haynes, Kemps, \& Moffitt, 2016).

It requires self-control to delay eating when delicious food is placed in front of you (Mischel \& Ebbesen, 1970). Further, it requires a long-term perspective to enjoy a favorite food kept until the end (Mischel, Shoda, \& Rodriguez, 1989). By contrast, impulsivity should be high in those who take a short-term perspective and eat what they like first rather than eating them later. However, few studies have examined the order of eating during one meal. Here we sought to expand the understanding of attitudes toward eating behavior and self-control by focusing on the order of eating a meal.

\subsection{Unconscious Control and Goal Shielding Theory}

Eating behavior is a daily activity. It is not always conscious, and many parts are habituated and automated. The same is true for attitudes toward eating behavior, such as ordering favorite foods (first or later). Unconscious control of habituation and automation (Oikawa \& Oikawa, 2010) is essential for daily living and can efficiently achieve desired goals. With unconscious control and automatic behavior, people do not experience conflicts because they no longer see unwanted goals as temptations (Gillebaart \& de Ridder, 2015). Goal shielding theory holds that when unwanted goals (temptation) are automatically suppressed, cognitively complete desires are more likely to suppress alternative goals (Shah, Friedman, \& Kruglanski, 2002). People who eat their favorite food later must automatically suppress the goal of eating what they like first and need to have a high degree of perfectionism to suppress their goal automatically. This study investigated how the cognitive desire for completeness is related to attitudes toward eating behavior. We tested the following hypothesis. The perfectionism scores of people who eat what they like later are higher than those who eat what they like first.

\subsection{Positive Emotion and Procrastination}

When people eat what they like first, they first eat their favorite food, making it easier for them to generate positive emotions. It is known that people with characteristic optimism and a tendency to expect positive results are more likely to make positive reinterpretations of problems they dislike and manage them better (Scheier \& Carver, 1985), and such people eat what they like first because they can easily use approach coping (Scheier, Weintraub, \& Carver, 1986).

Furthermore, eating what you like first can be regarded as putting off what you dislike. It is known that the tendency to procrastinate involves optimism and that optimistic procrastination leads to high positive emotions even during procrastination (Kohama, 2010). Therefore, we developed the following hypothesis: Optimism scores of people who eat what they like first are higher than the optimism scores of those who eat what they like later.

\subsection{Overview of Hypotheses in This Study}

The current study tested the following hypotheses: (1) Perfectionism scores of people who eat what they like later is higher than of people who eat what they like first; (2) Optimism scores of people who eat what they like first is higher than the optimism scores of people who eat what they like later. We conducted an internet-based survey to test these hypotheses by assessing the participant's optimism and perfectionism and asking them if they ate what they liked first or later. A $t$-test examined differences in perfectionism and optimism scores based on the eating order.

This study's theoretical and practical implications include extending the effect of perfectionism in goal shielding theory to the eating order and the behavior of postponing with what people like doing until later. Moreover, this study is expected to facilitate a deeper understanding of the relationship between the two personality types, perfectionism and optimism, in relation to self-control by applying these concepts to the eating order.

\section{Method}

\subsection{Participants}

An internet survey was conducted by a pooling company (Fastask). The participants were adults, randomly selected from monitors registered in Fastask, who responded to the questions. Monitor's responses without missing values were used in the analysis. The data of 564 participants (351 men and 213 women, age: $M=39.08$ years, $S D=11.34$, Range $=20-59$ ) were analyzed. The data of none of the respondents were excluded. We asked respondents to indicate whether they eat what they like first or later.

All the respondent's data were assigned unique IDs that were not related to the individuals to protect their privacy. In addition, the rules for the monitors have been established by Fastask, and only the monitors that agreed to the rules participated in this study. We explained the research purpose, question content, study period, 
voluntary participation, stopping participation in the middle, and personal information handling to the respondents on the first screen of the questionnaire implementation menu requesting the monitors to respond. We considered that the monitors had given their agreement by completing responses to all the questions. The current study was approved by the faculty ethics committee of the corresponding authors' university.

\subsection{Measures}

\subsubsection{Perfectionism}

The Multidimensional Perfectionism Cognition Inventory (Kobori \& Tanno, 2004; $\alpha=.90, M=3.16, S D=.62$ ), a 15-item scale, was used. Participants were asked to rate the extent to which each item applies to them by using a 5-point scale ranging from 1 (Does not apply) to 5 (Applies). Mean scores were analyzed.

\subsubsection{Optimism}

The Japanese Optimism and Pessimism Scale (Toyama, 2013; Optimism: $\alpha=.92, M=2.59, S D=.59$; Pessimism: $\alpha=.92, M=2.39, S D=.61$ ), which includes 20 items, was used. Participants rated the extent to which each item applies to them using a 4-point scale ranging from 1 (Does not apply) to 4 (Applies). Mean scores were analyzed.

\subsection{Analysis Design}

An independent samples $t$-test compared (1) optimism and (2) perfectionism scores of the two groups.

\section{Results}

The number of people who reported they eat what they like first ("first" group) was 259 , and the number of people who said they eat what they like later ("later" group) was 305.

Comparing optimism scores between the first and later groups indicated significant between-group differences (first; $M=2.68, S D=.56>$ later; $M=2.52, S D=.60 ; t(562)=3.22, p<.01, d=.27, \mathrm{CI}=.10$ to .43 ) with optimism significantly higher optimism scores in those who had their favorite food first compared to those that had it later, indicating that people who had their favorite food first were more optimistic than people who had it later. Moreover, comparing perfectionism scores between the first and later groups indicated marginal difference (first; $M=3.10, S D=.64<$ later; $M=3.20, S D=.60 ; t(562)=-1.86, p=.06, d=-.15, \mathrm{CI}=-.32$ to .00$)$ suggestive of a difference in eating order on perfectionism, such that people who had their favorite food later were more perfectionistic than people who had their favorite food first. However, these results were not significant.

It is not realistic to consciously perform all behaviors of daily life (Muraven, Baumeister, \& Tice, 1999). Human behavior is gradually and efficiently automated through the experience and learning that occurs from the stage at which attitudes toward eating behavior are not yet automated. Similarly, attitudes toward eating behavior become habitual and automated, and it can be said that meals are efficient when they reduce the consumption of mental resources. People who eat first may shield goals by their optimism, and people who eat later may shield goals by their perfectionism.

\section{Discussion}

The purpose of this study was to clarify the personality factors that determine differences in attitudes toward eating behavior and their mechanisms by focusing on the eating behavior of eating what you like first versus leaving it for later. Prior studies have shown that self-control is associated with reduced impulsive eating, reduced calorie consumption, alcohol restraint, and healthier eating behaviors (Muraven, Collins, \& Neinhaus, 2002; Tice, Bratslavsky, \& Baumeister, 2001; Vohs \& Heatherton, 2000). Few studies about self-control have examined effects on the order of eating a meal. We sought to develop the understanding of self-control and attitudes toward eating behavior by examining the relationship between factors of personality related to self-control and eating order. As a result, differences in optimism and perfectionist tendencies could be observed in the habituation and automation of attitudes toward eating behavior. In particular, optimism was involved in procrastination related to the eating order, such that people who have their favorite food first obtain positive feelings by eating what they like first and postponing eating what they dislike.

Previous studies have proposed that anticipation plays a crucial role in the task order in many people's choices about the timing of having aversive experiences. Harris (2012) reported that people select to undergo negative/aversive experiences sooner than later to minimize the experience of dread or painful anticipation, making it better to complete unpleasant tasks first because expectations increase by escaping from fear and waiting for fun later. In addition, Rosenbaum, Gong, and Potts (2014) and VonderHaar, McBride, and Rosenbaum (2019) examined procrastinating what you dislike, or doing things you dislike early; named "pre-crastination," which is defined as the tendency to complete or begin tasks as soon as possible even at the expense of extra physical effort (Rosenbaum et al., 2014). Moreover, the cognitive-load-reduction (CLEAR) 
hypothesis postulates a strong desire and drive to reduce the cognitive and working memory load (VonderHaar et al., 2019). Precrastination suggests the desire for early task completion and end-state comfort (Rosenbaum \& Sauerberger, 2019). The current study on eating behaviors contributes to recent research on the relationship between procrastination, pre-crastination, and task order, which is a crucial starting point for studying personality factors, such as perfectionism and cognitive desire for completeness in procrastination and pre-crastination.

Habbert and Achroeder (2020) suggested that people start with the most challenging task to increase efficacy, even though it is counterintuitive. However, it has also been indicated that people completing tasks in the order of increasing-easiness are less optimistic, feel worse, and experience reduced efficacy because of negative memories and failures (Weinstein \& Roediger, 2010). Therefore, increasingly complex tasks might result in more optimism. For example, people who eat their favorite food immediately have positive feelings. Therefore, it is necessary to understand individual differences in preferences and reaction times (Blinch \& DeWinne, 2019).

Future research is required to (1) investigate differences in the order of general tasks (difficulty-ordering), and the order of eating meals, (2) clarify how emotions and utilities are changing, based on personality factors as determined by focusing on eating order, which we are not conscious during everyday meals because eating what people like first or later are considered to be caused by individual differences, (3) clarify the influence of the family environment since childhood and parents.

No significant bias was found in the cross-tabulation by gender and age, suggesting that these variables do not affect the learning, habituation, and automation of eating behavior patterns, suggesting that a unique mechanism may underlie these behavior patterns. Because eating behavior encompasses events that everyone experiences throughout their lives, future studies must consider possible effects of environmental factors (Frankel, Powell, \& Jansen, 2018; Powell, Frankel, \& Hernandez, 2017) that could affect the timing of the formation of individual attitudes toward eating behavior from childhood to old age.

In summary, the results of this study suggest differences in the order of eating are related to optimism and perfectionism. Those who eat what they like first are more optimistic than people who eat what they like later, and those who leave what they like for later are more likely to be perfectionists. In addition, the present study may contribute to the development of interventions, including strategizing and goal setting, to reduce self-control failures such as overeating (Dohle et al., 2018; Duckworth, Milkman, \& Laibson, 2018; Schwartz, Just, Chriqui, \& Ammerman, 2017).

\section{About Conflicts of Interest}

The authors have no conflicts of interest related to the findings of this study.

\section{References}

Ali, Z., Wong, K., Egan, H., Cook, A., \& Mantzios, M. (2017). All you can eat buffets, obesity, mindfulness, and mindful eating: An exploratory investigation. Journal of Psychology and Psychiatry, 1, 1-5. https://doi.org/10.15761/JPP.1000101

Baumeister, R. F., Tice, D. M., \& Vohs, K. D. (2018). The strength model of self-regulation: Conclusions from the second decade of willpower research. Perspectives on Psychological Science, 13, 141-145. https://doi.org/10.1177/1745691617716946

Blinch, J., \& DeWinne, C. R. (2019). Pre-crastination and procrastination effects occur in a reach-to-grasp task. Experimental Brain Research, 237, 1129-1139. https://doi.org/10.1007/s00221-019-05493-3

Dohle, S., Diel, K., \& Hofmann, W. (2018). Executive functions and the self-regulation of eating behavior: A review. Appetite, 124, 4-9. https://doi.org/10.1016/j.appet.2017.05.041

Duckworth, A. L., Milkman, K. L., \& Laibson, D. (2018). Beyond willpower: Strategies for reducing failures of self-control. Psychological Science in the Public Interest, 19, 102-129. https://doi.org/10.1177/1529100618821893

Frankel, L. A., Powell, E., \& Jansen, E. (2018). The relationship between structure-related food parenting practices and children's heightened levels of self-regulation in eating. Childhood Obesity, 14, 81-88. https://doi.org/10.1089/chi.2017.0164

Gillebaart, M., \& de Ridder, D. T. (2015). Effortless self-control: A novel perspective on response conflict strategies in trait self-control. Social and Personality Psychology Compass, 9, 88-99. https://doi.org/10.1111/spc3.12160 
Harris, C. R. (2012). Feelings of dread and intertemporal choice. Journal of Behavioral Decision Making, 25, 13-28. https://doi.org/10.1002/bdm.709

Haynes, A., Kemps, E., \& Moffitt, R. (2016). Does trait self-control predict weaker desire for unhealthy stimuli? A lab-based study of unhealthy snack intake. Personality and Individual Differences, 89, 69-74. https://doi.org/10.1016/j.paid.2015.09.049

Jordan, C. H., Wang, W., Donatoni, L., \& Meier, B. P. (2014). Mindful eating: Trait and state mindfulness predict healthier eating behavior. Personality and Individual differences, 68, 107-111. https://doi.org/10.1016/j.paid.2014.04.013

Kobori, O., \& Tanno, Y. (2004). Development of multidimensional perfectionism cognition inventory. The Japanese Journal of Personality, 13, 34-43. https://doi.org/10.2132/personality.13.34

Kohama, S. (2010). Development, reliability, and validity of a scale of awareness of procrastination. Japanese Journal of Educational Psychology, 58, 325-337. https://doi.org/10.5926/jjep.58.325

Leyland, A., Rowse, G., \& Emerson, L. M. (2019). Experimental effects of mindfulness inductions on self-regulation: Systematic review and meta-analysis. Emotion, 19, 108-122. https://doi.org/10.1037/emo0000425

Mischel, W., \& Ebbesen, E. B. (1970). Attention in delay of gratification. Journal of Personality and Social Psychology, 16, 329-337. https://doi.org/10.1037/h0029815

Mischel, W., Shoda, Y., \& Rodriguez, M. L. (1989). Delay of gratification in children. Science, 244, 933-938. https://doi.org/10.1126/science.2658056

Muraven, M., Baumeister, R. F., \& Tice, D. M. (1999). Longitudinal improvement of self-regulation through practice: Building self-control strength through repeated exercise. Journal of Personality and Social Psychology, 139, 446-457. https://doi.org/10.1080/00224549909598404

Muraven, M., Collins, R. L., \& Neinhaus, K. (2002). Self-control and alcohol restraint: An initial application of the self-control strength model. Psychology of Addictive Behaviors, 16, 113-120. https://doi.org/10.1037/0893-164X.16.2.113

Oikawa, M., \& Oikawa, H. (2010). Consciousness and the unconscious in self-regulation: The effects of conscious compilation on goal priming. The Japanese Journal of Psychology, 81, 485-491. https://doi.org/10.4992/jjpsy.81.485

Powell, E. M., Frankel, L. A., \& Hernandez, D. C. (2017). The mediating role of child self-regulation of eating in the relationship between parental use of food as a reward and child emotional overeating. Appetite, 113, 78-83. https://doi.org/10.1016/j.appet.2017.02.017

Rosenbaum, D. A., \& Sauerberger, K. S. (2019). End-state comfort meets pre-crastination. Psychological research, 83, 205-215. https://doi.org/10.1007/s00426-018-01142-6

Rosenbaum, D. A., Gong, L., \& Potts, C. A. (2014). Pre-crastination: Hastening subgoal completion at the expense of extra physical effort. Psychological Science, 25, 1487-1496. https://doi.org/10.1177/0956797614532657

Scheier, M. F., \& Carver, C. S. (1985). Optimism, coping, and health: Assessment and implications of

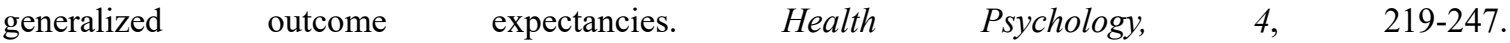
https://doi.org/10.1037/0278-6133.4.3.219

Scheier, M. F., Weintraub, J. K., \& Carver, C. S. (1986). Coping with stress: Divergent strategies of optimists and pessimists. Journal of Personality and Social Psychology, 51, 1257-1264. https://doi.org/10.1037/0022-3514.51.6.1257

Scholer, A. A., Miele, D. B., Murayama, K., \& Fujita, K. (2018). New directions in self-regulation: The role of metamotivational beliefs. Current Directions in Psychological Science, 27, 437-442. https://doi.org/10.1177/0963721418790549

Schwartz, M. B., Just, D. R., Chriqui, J. F., \& Ammerman, A. S. (2017). Appetite self-regulation: Environmental and policy influences on eating behaviors. Obesity, 25, 26-38. https://doi.org/10.1002/oby.21770

Shah, J. Y., Friedman, R., \& Kruglanski, A. W. (2002). Forgetting all else: On the antecedents and consequences of goal shielding. Journal of Personality and Social Psychology, 83, 1261-1280. https://doi.org/10.1037//0022-3514.83.6.1261 
Shimizu, H. (2016). An introduction to the statistical free software HAD: Suggestions to improve teaching, learning and practice data analysis. Journal of Media, Information and Communication, 1, 59-73.

Tice, D. M., Bratslavsky, E., \& Baumeister, R. F. (2001). Emotional distress regulation takes precedence over impulse control: If you feel bad, do it! Journal of Personality and Social Psychology, 80, 53-67. https://doi.org/10.1037/0022-3514.80.1.53

Toyama, M. (2013). Development of the Japanese optimism and pessimism scale: Reliability and validity. The Japanese Journal of Psychology, 84, 256-266. https://doi.org/10.4992/jjpsy.84.256

Vohs, K. D., \& Heatherton, T. F. (2000). Self-regulatory failure: A resource-depletion approach. Psychological Science, 11, 243-254. https://doi.org/10.1111/1467-9280.00250

VonderHaar, R. L., McBride, D. M., \& Rosenbaum, D. A. (2019). Task order choices in cognitive and perceptual-motor tasks: The cognitive-load-reduction (CLEAR) hypothesis. Attention, Perception, \& Psychophysics, 81, 2517-2525. https://doi.org/10.3758/s13414-019-01754-z

Weinstein, Y., \& Roediger, H, L. (2010). Retrospective bias in test performance: Providing easy items at the beginning of a test makes students believe they did better on it. Memory \& Cognition, 38, 366-376. https://doi.org/10.3758/MC.38.3.366

\section{Copyrights}

Copyright for this article is retained by the author(s), with first publication rights granted to the journal.

This is an open-access article distributed under the terms and conditions of the Creative Commons Attribution license (http://creativecommons.org/licenses/by/4.0/). 